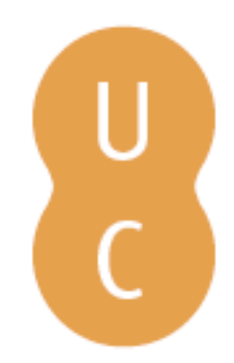

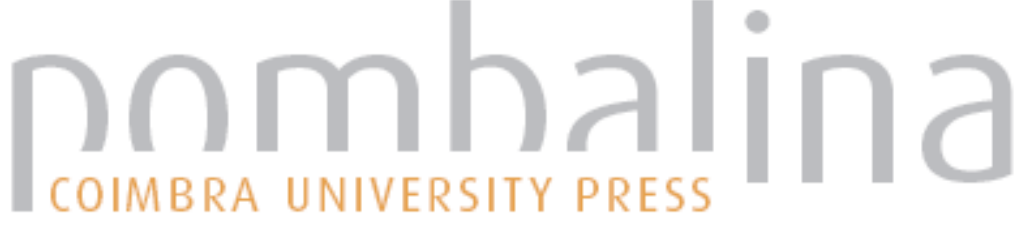

\section{Ilha de Moçambique: perfil sociológico}
Autor(es):
Ali, Momade
Publicado por: Imprensa da Universidade de Coimbra
URL persistente:
URI:http://hdl.handle.net/10316.2/44317
DOI:
DOI:https://doi.org/10.14195/978-989-26-1556-1_12

Accessed : $\quad$ 26-Apr-2023 10:47:07

A navegação consulta e descarregamento dos títulos inseridos nas Bibliotecas Digitais UC Digitalis, UC Pombalina e UC Impactum, pressupõem a aceitação plena e sem reservas dos Termos e Condições de Uso destas Bibliotecas Digitais, disponíveis em https://digitalis.uc.pt/pt-pt/termos.

Conforme exposto nos referidos Termos e Condições de Uso, o descarregamento de títulos de acesso restrito requer uma licença válida de autorização devendo o utilizador aceder ao(s) documento(s) a partir de um endereço de IP da instituição detentora da supramencionada licença.

Ao utilizador é apenas permitido o descarregamento para uso pessoal, pelo que o emprego do(s) título(s) descarregado(s) para outro fim, designadamente comercial, carece de autorização do respetivo autor ou editor da obra.

Na medida em que todas as obras da UC Digitalis se encontram protegidas pelo Código do Direito de Autor e Direitos Conexos e demais legislação aplicável, toda a cópia, parcial ou total, deste documento, nos casos em que é legalmente admitida, deverá conter ou fazer-se acompanhar por este aviso.

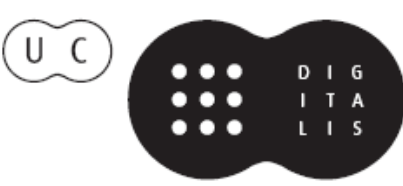




\section{OFICINAS DE \\ MUHIPITI \\ planeamento estratégico \\ património \\ desenvolvimento}

organização:

Walter Rossa

Nuno Lopes

Nuno Simão Gonçalves

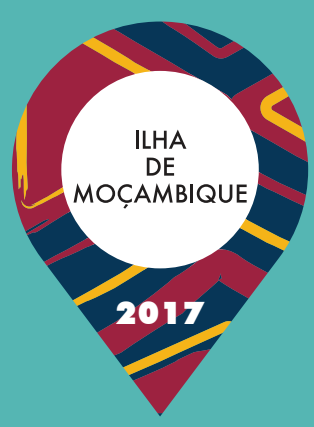




\section{ILHA DE MOÇAMBIQUE: PERFIL SOCIOLÓGICO}

Momade Ali

\section{INTRODUÇÃO}

Este artigo resulta da palestra feita no âmbito do Oficinas e visa descrever a evolução sócio-histórica da llha de Moçambique e as respetivas influências, considerando o seu valor patrimonial, consubstanciado na sua inscrição, em 1991, na Lista do Património Mundial da UNESCO, e tendo em vista os desafios da sua preservação.

\section{BREVE CONTEXTUALIZAÇÃO HISTÓRICA}

A interpenetração das duas correntes culturais (a do interior e a costeira, local e continental) é um dos aspetos principais da história da costa oriental da África durante os últimos 2.000 anos, tendo constituído uma nova amálgama, a civilização costeira swahili.

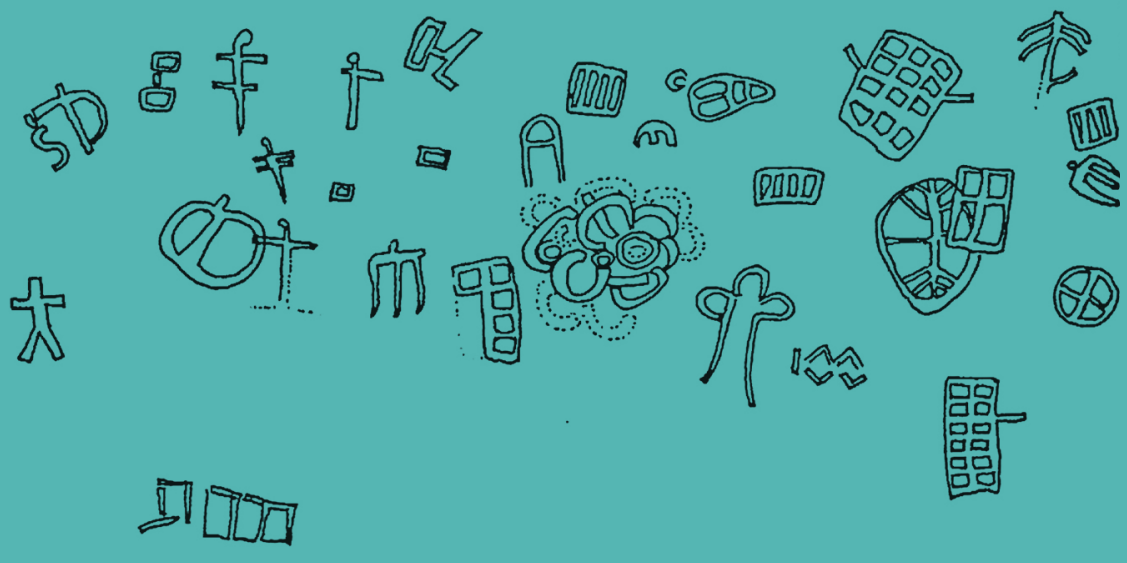


No caso concreto de Moçambique, Mutiua (2015: 234) refere que as migrações de diferentes povos tais como os bantu, originários da África Ocidental, assim como de povos asiáticos e outros do vasto Oceano Índico, de europeus e ainda dos nguni, provenientes da região da atual África do Sul (também conhecidos como mfeqane), marcaram o panorama demográfico e social da costa norte do país e influenciaram os processos políticos e económicos, culturais e religiosos da região entre os finais do século XIX e princípios do século XX.

Pode, então, afirmar-se que a matriz histórica e sociocultural da llha é fundamentalmente resultado dessas dinâmicas locais, regionais e globais que se condensam em movimentos migratórios impulsionados pela necessidade de sobrevivência, incluindo o comércio e a exploração de recursos como o ouro, o marfim, a borracha e, mais tarde, o tráfico de escravos. Os wak-wak, proto-bantu, ou khoi-san, refere Mutiua, foram os povos que interagiram com os primeiros imigrantes bantu que chegaram à região entre 3000 a.C. e 1100 d.C.

No início do século XVII, uma nova onda migratória vinda da região central de África, trouxe os maravi, os quais conquistaram a região através de violentos ataques militares, impondo-se sobre os restantes habitantes, passando a controlar o comércio a longa distância que ligava o hinterland ao Oceano Índico, até ao início do século XIX. Na primeira metade do século XIX, fatores ecológicos, políticos e económicos forçaram os ngunis a um processo migratório designado mfeqane, considerado o maior fator de reconfiguração política, demográfica, social e linguística na região (Mutiua, 2015: 235-238).
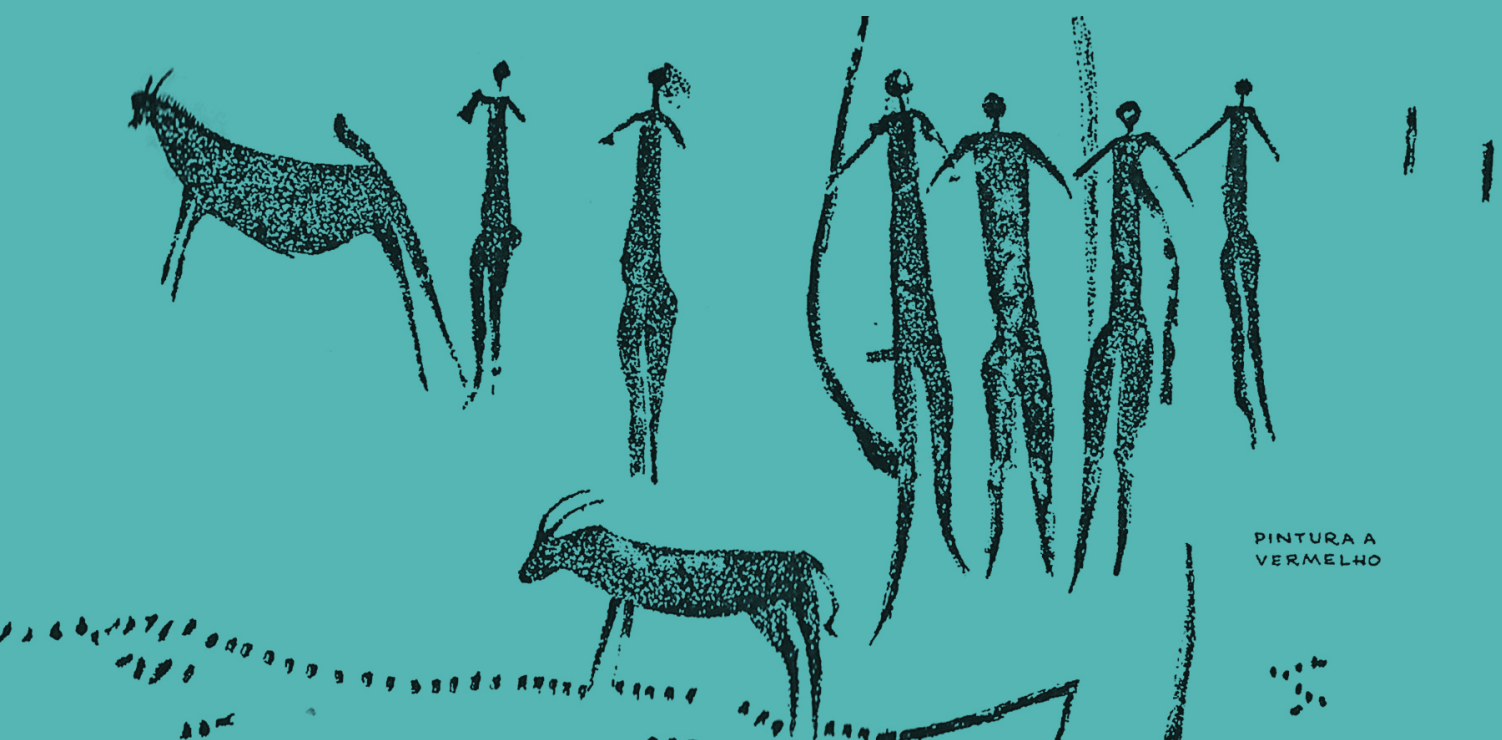


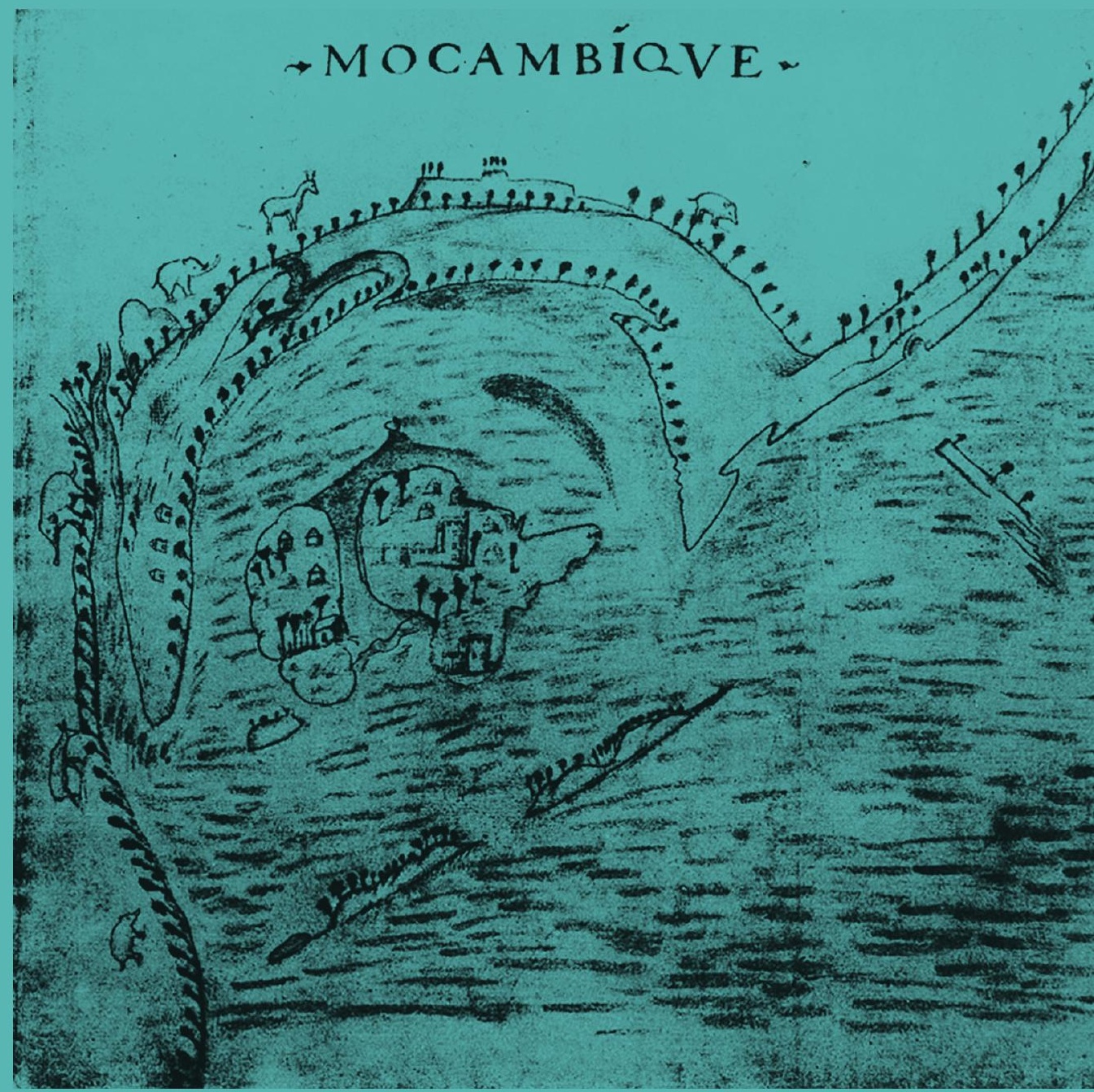

A chegada dos Portugueses, em 1498, chefiados por Vasco da Gama, teve também um impacto significativo na organização política, económica e social na região, favorecendo, por exemplo, a concentração dos principais entrepostos ou assentamentos comerciais sob o controlo dos swahili no norte de Moçambique. Angoche e a Ilha de Moçambique foram, até o século XIX, os principais centros do Islão, através dos emigrantes das cidades swahili de Quíloa e Zanzibar, movidos por razões comerciais, principalmente o comércio do ouro. 


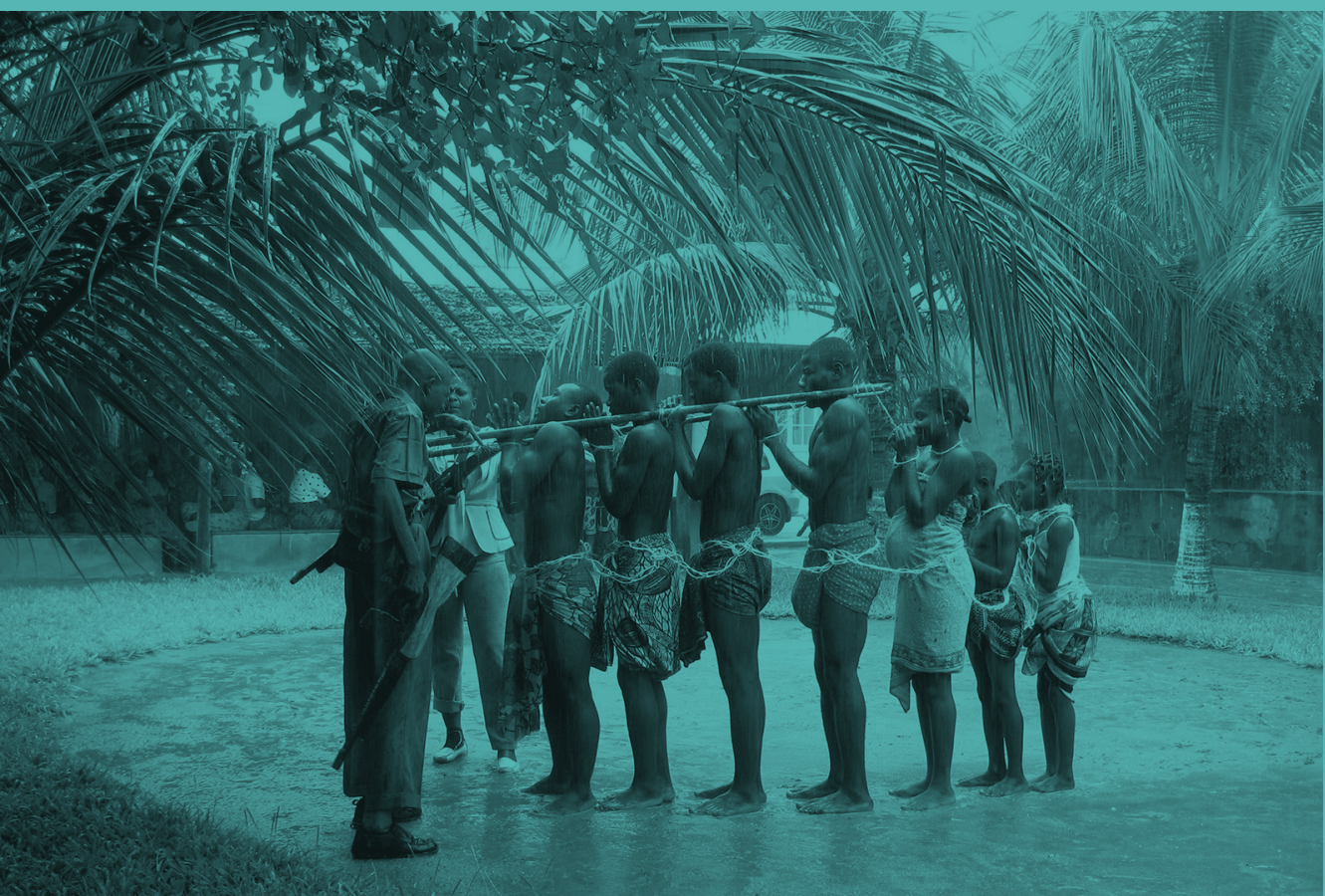

O comércio de escravos tornou-se devastador e significativo durante os séculos XVIII e XIX, sendo os principais operadores da região os Franceses, os Portugueses, os Ayao e os Swahili, tendo como principal fonte a makhuwana. Os escravos provenientes dessa região eram exportados para as Mascarenhas, Comores, Madagáscar, Zanzibar, Golfo Pérsico, Brasil e Cuba, enquanto o ouro tinha como principal destino a Índia (Mutiua, 2015).

Para Aurélio Rocha (2000: 111-112), "foram as classes dominantes desses reinos swahilizados que asseguraram, em todo o século XIX, a exportação clandestina de escravos para Zanzibar, Madagáscar e Golfo Pérsico, após a proibição do tráfico em 1836 e, mais tarde, em 1842". Seja como for, ao possibilitar permanências duradouras, as atividades comerciais acabaram por estabelecer novas estruturas sociais e políticas, fazendo emergir na região costeira do norte de Moçambique uma moldura cultural, histórica e patrimonial com influências locais, regionais e continentais. As sociedades litorâneas constituíram-se em sultanatos e xeicados, com influências de Quíloa e do Zanzibar. 


\section{NOVAS DINÂMICAS, NOVOS DESAFIOS}

Insiste-se na ideia de descrever o perfil sociológico da Ilha sempre em atenção à sua história e cultura, porquanto não se vislumbra outro modo de fazê-lo, tentando definir os desafios que as novas dinâmicas (sociais, políticas e económicas) impõem a esse território e à sua população.

Devido à sua peculiaridade e ao seu valor histórico e cultural, a Ilha de Moçambique foi inscrita, em 1991, na Lista do Património Mundial da UNESCO. Portanto, de acordo com Omar e Júnior, é necessário reconhecer diferentes tipos de bens patrimoniais na Ilha, marcados por processos de constituição e de exclusão, que hoje tornam bastante complexa a definição e preservação do património. A própria linguagem, anotam os autores, regista essa segregação através do idioma, "reservando o português para designar o material construtivo (pedra e cal) da cidade portuguesa, e o emakhuwa [...] para designar a cidade cuja ocupação começou com os escravos que vinham trabalhar na construção da Cidade de Pedra e Cal" (Omar e Júnior, 2015: 5). Estes processos "remetem às demarcações sociais que hoje definem também a institucionalização do património da Ilha, entretanto sem um aprofundamento dos significados nesse processo institucional" (idem, 2015: 57). Do ponto de vista sociológico, acrescentam, a inscrição da Ilha na Lista do Património Mundial, assim como os respetivos esforços da sua conservação e preservação, enfrenta uma herança histórica da divisão espacial pautada pela segregação, que correspondeu a uma "autêntica clivagem socioeconómica e cultural desde o período colonial, visto que a cidade de macuti, por exemplo, sempre foi [e continua] uma zona com um nível social e económico vulnerável em relação à [cidade de Pedra e Cal], facto que mesmo nas atuais políticas [...], torna difícil encontrar mecanismos de gestão global." (2015: 8). Esta será a primeira realidade a superar em qualquer tentativa de redescoberta, conservação e usufruto das riquezas (históricas, socioculturais e turísticas) da llha. É importante, igualmente, considerar as características da população, relevando a pressão demográfica que o território enfrenta desde as últimas décadas do século passado (Teixeira, 2007). 
As estatísticas de 2012 do distrito da Ilha de Moçambique — que tem uma superfície de $445 \mathrm{Km}^{2}$ e uma densidade de 287,7 hab./ $\mathrm{Km}^{2}$ apresentam-nos os seguintes dados demográficos (INE, 2012):

\begin{tabular}{|c|c|c|}
\hline TOTAL & 52.962 & \\
\hline Grupos & Número & $\%$ \\
\hline Mulheres & 27.114 & 51.2 \\
\hline Homens & 25.848 & 48.8 \\
\hline $0-4$ anos & 8.450 & 16 \\
\hline $5-14$ anos & 13.873 & 26.2 \\
\hline $15-64$ anos & 28.233 & 53.3 \\
\hline
\end{tabular}

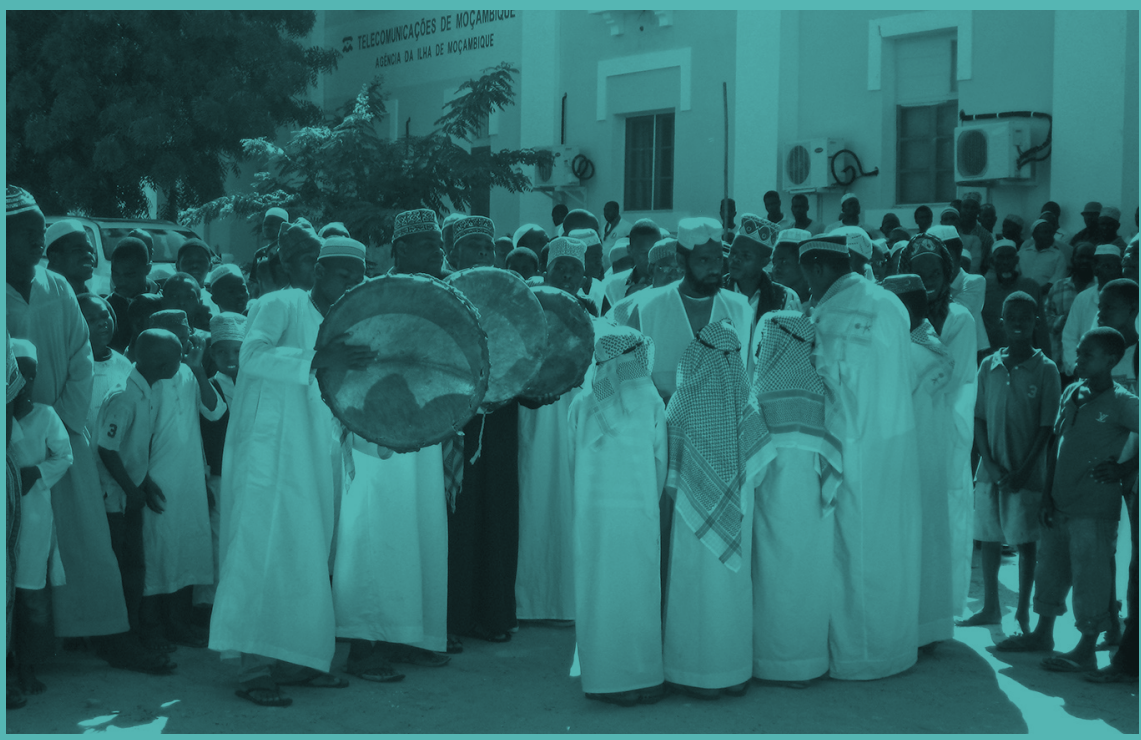

Mais de $90 \%$ da população fala emakhuwa - variante enahara, influenciada pelas línguas árabe e swahili - e professa a religião islâmica. No que diz respeito à alfabetização, compreensivelmente o grupo etário dos 15-19 anos, com 34.5\%, tem a menor taxa de analfabetismo, e o grupo dos mais de 60 anos a maior, com $70.8 \%$ (INE, 2012: 15). 


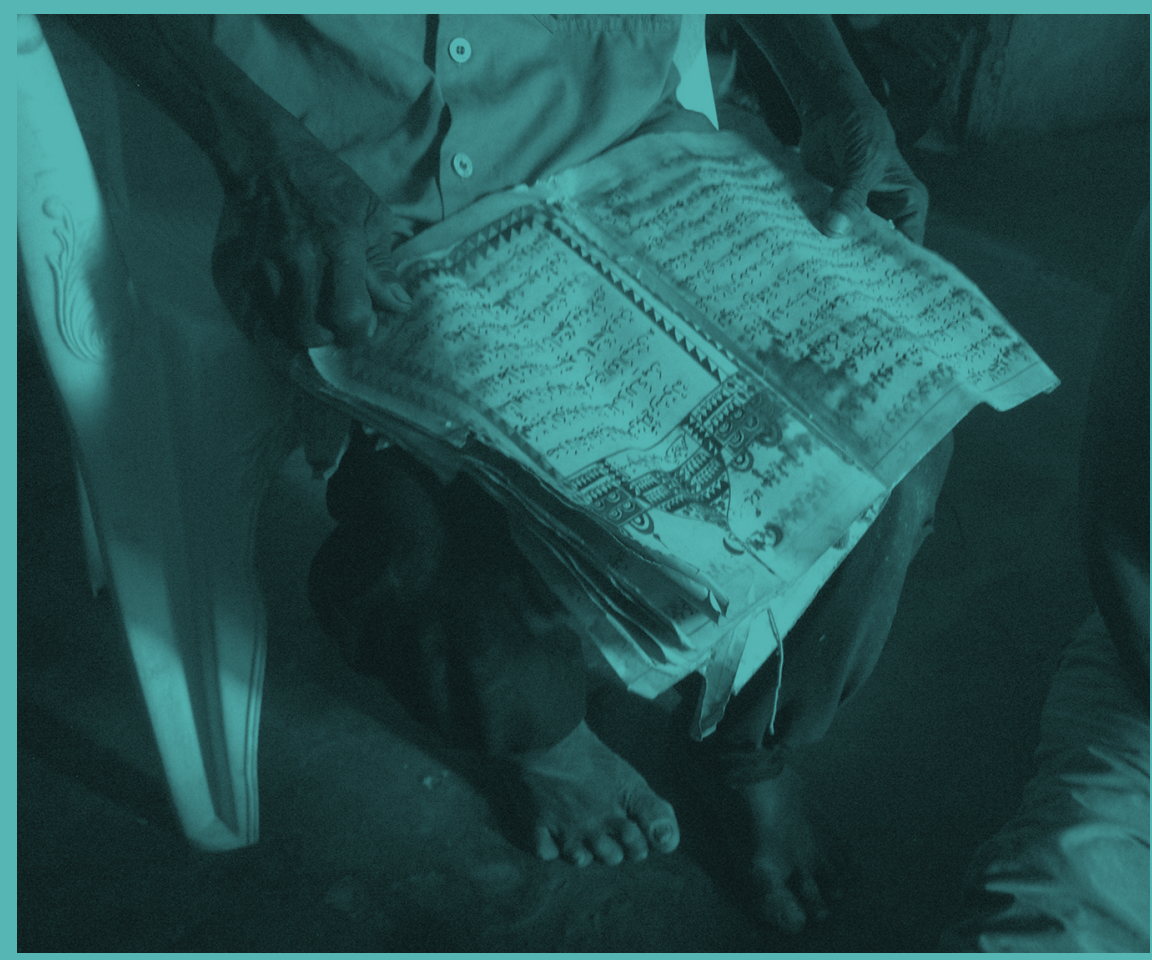

Por entre os indicadores de bem-estar, é relevante destacar que, no que diz respeito ao sistema construtivo das habitações, as casas de adobe e/ou paus maticados representam $63.6 \%$ do total, sendo que $76.8 \%$ têm cobertura de capim, colmo ou macuti; e que em relação a bens duráveis, 38\% dos agregados possuem rádio, $9.3 \%$ televisão, $19.2 \%$ bicicleta e $54.5 \%$ não possuem nenhum.

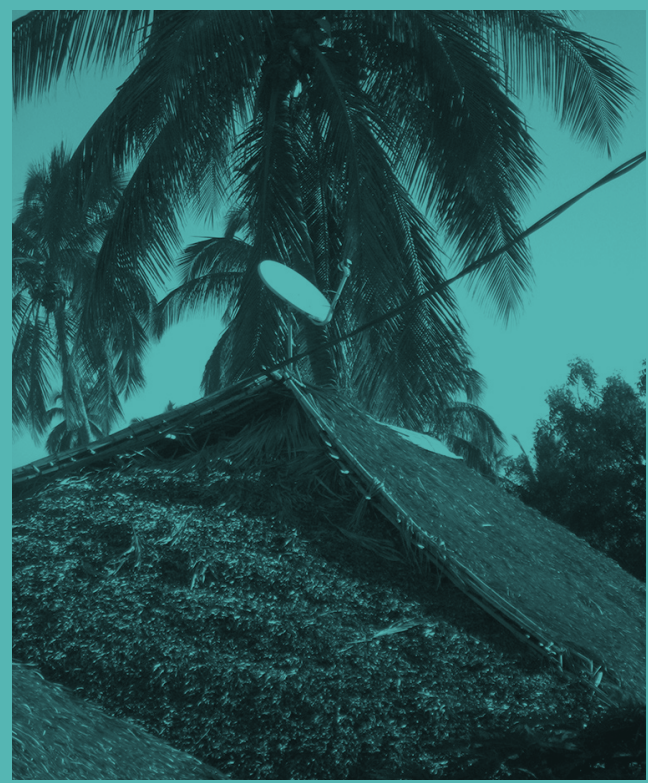


Em termos de indicadores sociodemográficos, particularmente:

Em 2011, o setor educativo público tinha no território um total de 14 escolas primárias do $1^{\circ}$ grau e 11 do $2^{\circ}$ grau. Havia também 4 escolas secundárias públicas do $1^{\circ}$ ciclo e igual número de privadas, 4 escolas secundárias públicas do $2^{\circ}$ ciclo e igual número de privadas. Com a abertura da Faculdade de Ciências Sociais e Humanas, em 2016, a UniLúrio (que, em 2011, ali criara o Centro de Estudos e Documentação da Ilha de Moçambique) tornou-se na primeira instituição de ensino superior a instalar-se na Ilha.

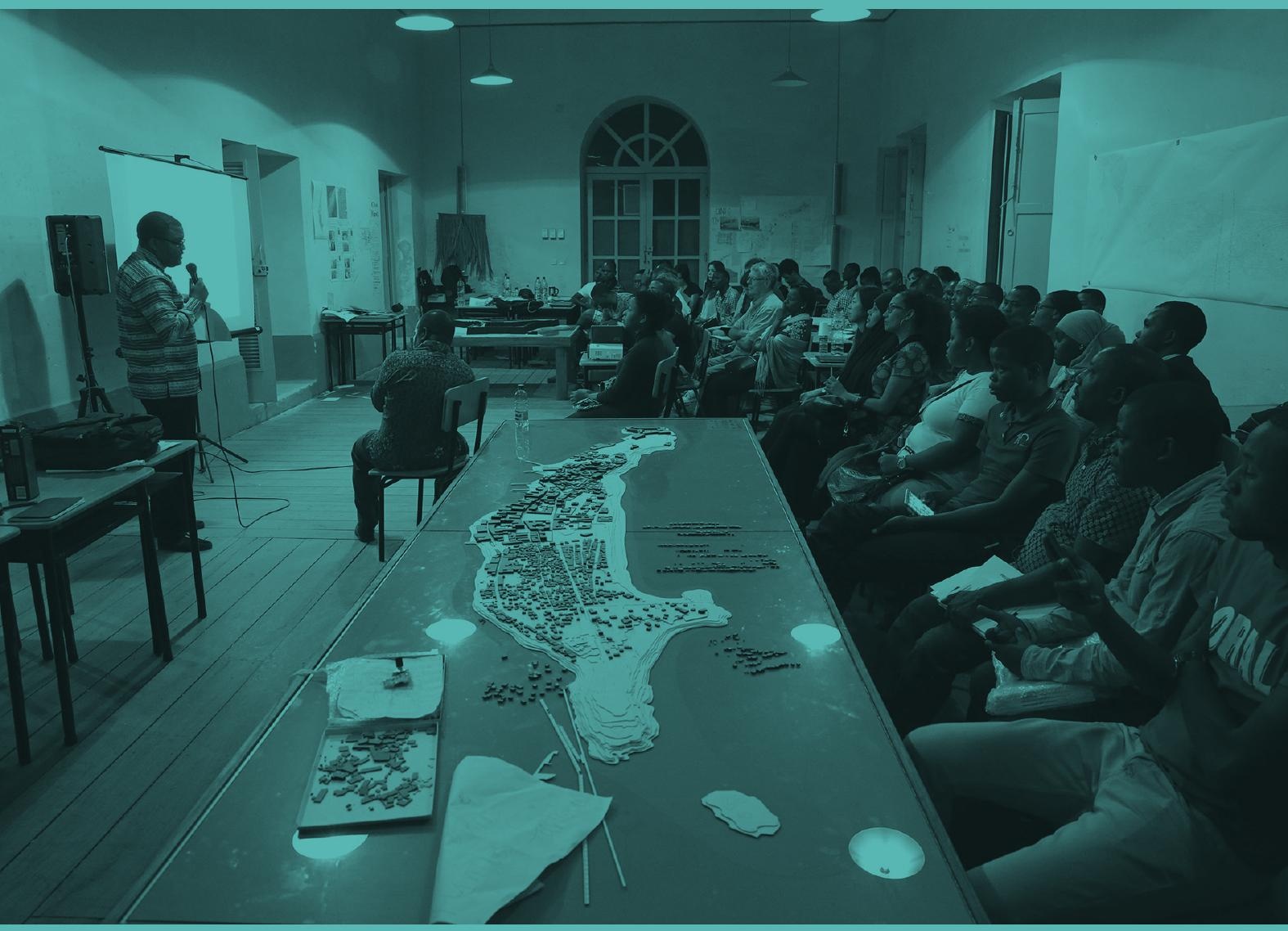




\section{CONSIDERAÇÕES FINAIS}

Concluindo este breve retrato sociológico da llha, cabe invocar a síntese de José Pimentel Teixeira (2007), que descreve o perfil sociológico do distrito da llha de Moçambique como de predominância linguística do emakhuwa nas relações de sociabilidade locais, prevalência da religião islâmica, e de acentuado crescimento demográfico e urbanístico.

Contudo, e com base nos dados de bem-estar, constata-se que, em geral e à semelhança do país, o distrito da Ilha de Moçambique vive uma situação de pobreza, destacando-se fatores que contribuem para as difíceis condições de vida que nela residem, em especial a elevada densidade populacional, as características climáticas (que facilitam a propagação de várias doenças), e "uma economia limitada em todos os seus sectores, que não permite a criação de empregos e que, consequentemente, leva à impossibilidade de os agregados familiares possuírem recursos suficientes e satisfatórios" (Patrão e VasconcelosRaposo, 2011: 152). Para além do comércio, a população vive da agricultura, da pesca, da pecuária, da indústria e do turismo.

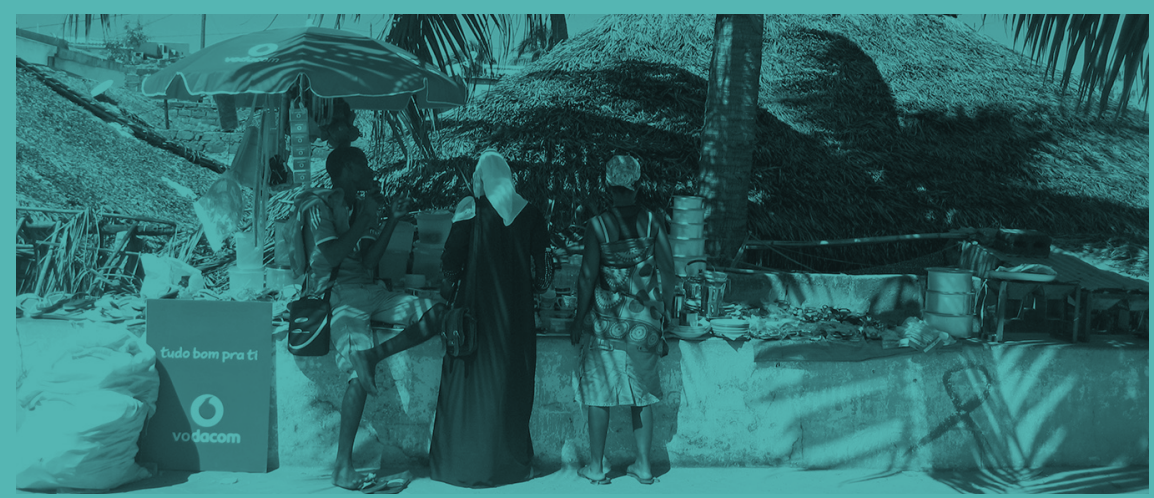

Por tudo isso, as intervenções sociopolíticas não se deverão resumir em ações paliativas, superficiais ou de contingência, mas sim integrar um substrato institucional com efeitos de médio e longo prazo na educação e cultura, através da formação de uma nova geração de profissionais qualificados, capazes de oferecer soluções de desenvolvimento local e comunitário. 


\section{REFERÊNCIAS BIBLIOGRÁFICAS}

Instituto Nacional de Estatística (2012), Estatísticas do distrito da Ilha de Moçambique. Governo de Moçambique: INE.

MUTIUA, Chapane (2015), "O Norte de Moçambique entre os séculos XIX e XX" in Teresa Cruz e Silva et al. (orgs.). Comunidades Costeiras: perspectivas e realidades. Maputo: CESAB.

OMAR, Lúcia; JÚNIOR, Euler (2015), "Património cultural e memória social na Ilha de Moçambique", Revista CPC, 18, 4-28. São Paulo.

PATRÃO, Ana Luísa; VASCONCELOS-RAPOSO, José (2011), "O Estado de Saúde da Ilha de Moçambique: Uma análise comparativa dos indicadores de saúde da população". Cadernos de Estudos Africanos, 21, 147-161.

ROCHA, Aurélio (2000), "Os reinos afro-islâmicos da costa" in Carlos Serra (dir.), História de Moçambique, vol.1. Maputo: Imprensa Universitária. 111-126. ${ }^{1} 1993$.

SHERIFF, Abdul (2011). "A costa da África Oriental e seu papel no comércio marítimo" in Gamal Mokhtar (coord.), História Geral da África. II. A África antiga. São Paulo/UNESCO: Ática/Paris. ${ }^{1} 1983$.

TEIXEIRA, José Pimentel (2007), Conteúdos comunitários na área da llha de Moçambique face a projectos de desenvolvimento. Relatório de Consultoria para o Banco Africano de Desenvolvimento. 